\title{
LA OLIGARQUía URBANA EN LA EDAD MODERNA 1
}

\section{por \\ ENCARNA GARCÍ MONERRIS}

Universitat de València

El trabajo de Mauro Hernández nos ofrece un exhaustivo estudio sobre un reducido grupo social, pero no por ello irrelevante, que gobernó en la villa de Madrid a lo largo de los siglos XVII y xviI. Se ocupa, pues, del poder a escala local, pero no es un trabajo de historia institucional. Si bien en un príncipio fue ésta su acta de nacimiento, como parte de un proyecto más amplio sobre el Madrid de la Edad Moderna, acabó siendo "un estudio de historia social», con un objeto bien preciso: la oligarquía urbana madrileña durante los siglos xvi y xviI.

El autor nos va exponiendo los resultados de su trabajo a lo largo de siete minuciosos capítulos, que se ven complementados y documentados por un considerable número de apéndices, en los que podemos encontrar la más variada información sobre los regidores madrileños (extracción social, edad en el momento de acceder al cargo, fortunas, árboles genealogicos, etc.). Para ello, se ha servido de las fuentes que le ofrecen archivos tales como el de la Villa de Madrid, en sus diversas secciones, el Histórico Nacional, o el General de Simancas, sin olvidar las enormes posibilidades abiertas por la consulta de los fondos que conforman el archivo privado de la que fue una de las familias de regidores más destacadas, los condes de Campo Alange.

En un primer apartado, Mauro Hernández nos introduce en el espacio urbano y político en el que se va a desarrollar la acción de los sucesivos capitulos. Un espacio urbano, el de la villa de Madrid, que cambiará de imagen y de funcionalidad desde que Felipe II, en 1561, decidiera convertirla en capital de la Monarquía. Ciertamente no fue éste un acontecimiento sin importancia. Antes al contrario, el «impacto de la Corte» sería decisivo para el futuro

I Mauro Hernández, a la sombra de la Corona. Poder local y oligarquía urbana (Madrid, 1606-1808). Siglo xxl, Madrid, 1995. ISBN: 84-323-0874-9. 424 págs.

Hispania, LV1/3, núm. 194 (1996) i!21-113! 
social, político y urbanístico de la misma. Un futuro que, a partir de ese momento, se va a mostrar lleno de contrastes derivados, en última instancia, de la dicotomía Corte-Villa, y que no podían dejar de influir y de mediatizar en el gobierno urbano y en quienes se instalaron al frente del mismo. Un gobierno, por supuesto, distinto al de la Corte y al de los aparatos de la Monarquía allí ubicados.

Los protagonistas del resto del libro son los regidores, la oligarquía urbana madrileña de los siglos XVII y xVIII. Pero se trata de un protagonismo que no pueden dejar de compartir con quien conviven y con quien, en definitiva, les dio vida: la Monarquía. Desde el siglo XVI, los reyes hispanos, no ajenos a lo que en otros reinos vecinos acontecía, se adentran por el camino de la centralización administrativa. La "sedentarización de la Corte» y las variaciones y evolución que sufrirá la oligarquía de regidores y con ella el poder municipal a lo largo del tiempo, serán, entre otras muchas, algunas de las manifestaciones de ese amplio y complejo proceso que no iba a tener ni un único responsable, ni un sólo beneficiario.

Pero ¿cuál es el "perfil» social, económico y político de esa oligarquía? La respuesta a este plural interrogante la encontramos en los restantes apartados del trabajo, unas veces de forma monográfica en alguno de ellos, otras dispersa a lo largo de todo el estudio, pero no por ello de forma desordenada. No hay posibilidad de que el lector olvide en algún momento quiénes son los personajes centrales, ni cuáles sus rasgos definitorios básicos.

El Madrid de la Edad Moderna atraviesa por distintos momentos o etapas, en cada uno de los cuales su oligarquía sufre también modificaciones en términos de composición. Así, siguiendo al autor, entre 1561 y 1630 se asiste a un proceso de renovación que comporta la entrada de sectores burgueses (banqueros, comerciantes, empleados de la administración e hidalgos de ejecutoria) en el gobierno de la villa y la reducción del número de hidalgos de sangre; todo ello acompañado de una práctica inversora en tierras. Entre 1630 y 1750, aproximadamente, se da una fase de kestancamiento» y «definición» tanto de la urbe como de los regidores que la gobiernan, calificada por Mauro Hernández en términos de "refeudalización»: la oligarquía se dota de atributos nobiliarios, se conforma como un grupo homogéneo, privilegiado, que se va a aprovechar de las posibilidades que la Monarquía le ofrece, no sólo en términos de poder político-institucional al frente del Concejo, sino también en términos patrimoniales. El acceso a la propiedad urbana, las rentas (censos, juros y efectos de villa) y los oficios públicos van a ser durante bastante tiempo sus principales fuentes de ingresos y la parte más importante de sus patrimonios. Nos encontramos ante estrategias económicas de corte rentista, muy "ligadas a las arcas del Estado" y que participan de su fiscalidad. Es, pues, una oligarquía inserta «en los mecanismos de detracción de la renta feudal centralizada» (pág. 272). Desde mediados del siglo xvII, y hasta la crisis final del Antiguo Régimen, la peculiar estructura social que se ha ido consolidando en el período anterior empieza a mostrar sus «limitaciones", sobre todo por lo que se refiere al crecimiento económico, No quiere decir esto que en el seno de la oligarquía urbana de regidores no se operen cambios. Ya 
desde comienzos del setecientos algunos de ellos dirigen una parte importante de sus inversiones hacia la tierra de pastos y el ganado lanar, constituyendo este último un rentable negocio para muchas familias ligadas al poder local. Al mismo tiempo, y en el contexto del reformismo borbonico de la segunda mitad del siglo XVIII, el desinterés - aunque no general- mostrado por los empleos de regidor permitirá el acceso al Concejo de individuos cuya procedencia social y actividad economica difieren sustancialmente de las de quienes han monopolizado el Ayuntamiento madrileño durante cerca de siglo y medio. Estaríamos ante la burguesía comercial que accede tarde y en número reducido a un espacio de poder que formalmente le había estado prohibido.

En efecto, en 1603, Felipe III concede un privilegio por el que se va a dotar al Ayuntamiento de Madrid de un Estatuto de regidores: esto es, de un conjunto de requisitos que teoricamente debian cumplir quienes aspirasen a una plaza en el mismo, y de los que sobresalen la condición de hidalguía y la de no realización de oficios mecánicos. La exigencia de limpieza de sangre sólo se hará explícita a partir de 1638. Ahora bien, como el autor advierte, una cosa es la normativa vigente y otra la aplicación de la misma. Es cierto que el Estatuto supuso la wculminación de un proceso de cierre social que surge como respuesta de las oligarquías a las ventas y acrecentamientos de oficios municipales» realizadas por la Monarquía (pág. 56). Ahora bien, aquél no tuvo una aplicación estricta; en muchas ocasiones se prescinde de él, entrando en el Ayuntamiento individuos procedentes del mundo del comercio o de los negocios en general, que, una vez en el poder, adoptan pautas de comportamiento claramente nobiliario.

De este modo, la oligarquía madrileña, sin negarse rotundamente a la posibilidad de renovarse - a través sobre todo de las ventas de regidurías entre particulares-, se protege a sí misma como grupo que se autoclausura, más o menos homogéneo, y al poder que ha reunido. Pero también la Monarquía obtiene beneficios de esta práctica: «Se trataba, sobre todo, de no enajenarse voluntades: ni las de la nobleza tradicional consagrando legalmente el ascenso social de los nuevos sectores, ni la de estos grupos pujantes, adinerados y ya poderosos que constituían un pilar tan leal como la aristocracia tradicional» (pág. 60).

En estas últimas palabras del autor podemos ver sintetizado el que fue uno de los rasgos distintivos del absolutismo monárquico: ampliar la base social que lo iba a sustentar, sin quebrantar en lo fundamental el status quo. Esto es, creando un nuevo tipo de "nobleza», de orígenes diversos, que se integra en el seno del estamento privilegiado. Y todo ello gracias a la Monarquía, gracias a la posibilidades que ésta le brinda para ocupar espacios de poder local- y desde ellos ascender en la escala social y económica. Merced a este mecanismo, se va configurando en el Ayuntamiento madrileño un grupo oligárquico al que el autor define como «burguesía feudal», una burguesía que participa de las prácticas económicas y sociales del Antiguo Régimen: que, por la estructura de los patrimonios de una parte de la misma, puede decirse de ella que no invierte en la producción que depende del empleo estatal y que 
desarrolla estrategias económicas de corte rentista, "particularmente ligadas a las arcas del Estado, de participación en la fiscalidad, ya sea bajo la forma de juros, efectos u oficios..... Es decir, que está integrada "en los mecanismos de detracción de la renta feudal centralizada" (pág. 272).

Si esto es asi desde el punto de vista socio-económico, ¿cuál fue su actitud política? A lo largo de todo el trabajo, pero de forma ya totalmente explícita en el último de los apartados, el autor afirma que dicho grupo social oligárquico, constituido como representante de la «burguesía feudal», tal y como recordábamos, tiene un proyecto político coincidente, en sus "intereses fundamentales", con el de la Corona. Institución ésta que, por lo demás, sigue siendo no obstante preeminente, sobre todo cuando se plantean situaciones de conflicto con las ciudades y su nivel de competencias o autonomía. Con la claridad que caracteriza a todo el texto, Mauro Hernández nos lo resume así:

"Si en la Castilla del Xvi resulta tan difícil hallar los rastros de un poder urbano es precisamente porque las oligarquías han renunciado a él, para apostar por el proyecto de refeudalización del absolutismo. Así, se convierten en burguesía feudal, ligando su suerte a la de un Estado absoluto comprometido en la defensa del feudalismo. De ahí que los rasgos más nítidos de estas oligarquías sean precisamente su vinculación al Estado y, en última instancia, a integrarse en la nobleza titulada» (págs. 300-301).

Con tales argumentos, basados en parte en los resultados de su propio trabajo, y en parte en las aportaciones de otros autores, como, por ejemplo, Bartolomé Yun en su estudio sobre la transición al capitalismo en Castilla ${ }^{2}$, Mauro Hernández sale al paso de lo que vienen siendo dos visiones o tesis diferentes dentro de la historiografía modernista, sobre el poder de las ciudades, sus oligarquías y el poder monárquico o del "Estado", utilizando una terminología frecuente en el autor. En efecto, "el estudio de la oligarquía madrileña - apunta - nos permite proponer una revisión de la versión liberal de la decadencia del municipio castellano", recuperando aquello que es su «aspecto más convincente». Es cierto que fueron varias las facetas de su gobierno que, tras la derrota de las Comunidades, tuvieron que sucumbir víctimas de la centralización y de los intereses monárquicos. Su grado de autonomía se vió sensiblemente mermado. Sin embargo, la oligarquización de los concejos que acompañó a este proceso no iba a responder únicamente a los intereses de una de las partes, esto es, a los de la Monarquía, sino también a los de esos sectores sociales que, desde una posición de no privilegiados, no tardarían en hacer coincidir su proyecto político con el de la institución que les abría las puertas del poder, aunque éste fuera a escala local. Se inicia as ́ una relación no demasiado conflictiva, sino de colabora. ción, en la que, sin descartar ni olvidar el intervencionismo regio en sus

2 YUN CASAlilla, B., Sobre la transición al capizalismo en Castilla. Economía y Sociedad en Tierra de Campos (1500-1830). Valladolid, Junta de Castilla y León. Consejería de Educación y Ciencia, 1987.

Hispania, LVI/3, núm. 194 (1996) 1121-1131 
diversas manifestaciones, también iba a tener cabida una «limitada autonomía municipal».

Se evita, de este modo, caer a su vez en lo que para el autor es la radicalidad de la tesis mantenida por algunos autores frente a la tradicional visión liberal. Se trata de una tesis en la que el excesivo protagonismo concedido al "Estado" y al desarrollo del mismo en el devenir de la historia moderna Europea, cede paso al protagonismo de las Cortes - y con ellas a las ciudades-. Las dificultades hacendísticas de la Corona explican su alto grado de intervencionismo en los niveles de poder inferiores, pero al mismo tiempo la hacen depender de los "servicios" que dichas Cortes aprueben a favor de aquélla. Desde este punto de vista, tanto el grado de centralización monárquica como la pérdida de autonomía municipal deben relativizarse, recuperándose la idea y la praxis del poder político de las ciudades en la Edad Moderna. Un poder no exento de problemas en su relación con los otros poderes, pero sin llegar a alcanzar nunca un alto grado de antagonismo. Faltaría, sin embargo, en esta interpretación más reciente, definir las oligarquias urbanas en ese contexto, según el autor.

$Y$ es en este punto en el que propone cuál es la síntesis resultante de lo que son dos interpretaciones diferentes de un mismo problema histórico: tal y como indicábamos reproduciendo textualmente sus palabras, las oligarquías urbanas castellanas, desde muy temprano renuncian a un proyecto político propio y hacen suyo el de la Monarquía absoluta. Esto implicará niveles altos de dependencia y de subordinación de los gobiernos locales respecto a aquélla, pero también hará posible que esa "burguesía feudal" se reproduzca de forma autónoma, se enriquezca, alcance títulos nobiliarios y sea uno de los pilares fundamentales de la implantación del absolutismo en las ciudades.

Evidentemente son muchas las cuestiones y referencias de detalle que el autor aporta a lo largo de su trabajo, y en las que no podemos ni debemos entrar por no ser este el lugar adecuado. Todas ellas no hacen sino dar cuenta de que se trata de un minucioso trabajo, de historia local si así se le quiere denominar, pero cuyos parámetros teóricos nos transportan hasta una problemática histórica e historiográfica de mayor alcance, cual es la del poder político y social en la España de la Edad Moderna, su estructura y su naturaleza en el marco del absolutismo monárquico. Hace ya algunos meses, Santos Juliá se refería a esta obra como una «magnífica muestra de la calidad de la historia local ha alcanzado durante los últimos años en España» (El País, 27 de mayo de 1995). Por nuestra parte, no hay inconveniente alguno en compartir tal valoración. Incluso, podríamos añadir que una lectura atenta de la misma nos ha permitido aprender, hasta el extremo de poder afirmar que si en estos momentos tuviéramos que reescribir lo que fue nuestra tesis doctoral sobre la oligarquía urbana valenciana del setecientos ${ }^{3}$, no podríamos dejar de contar con este trabajo.

3 Garcia MonerRis, E., La Monarquía absoluta y el municipio borbónico, La reorganización de la oligarquía urbana en el Ayuntamiento de Valencia (1707-1800). Madrid, Consejo Superior de Investigaciones Científicas, 1991. 
Ahora bien, precisamente porque la lectura que hemos hecho del libro ha querido ser minuciosa e interesada, son varias las cuestiones, los problemas, que, pensamos, pueden ser objeto de discusión. Nuestro propósito aquí no es responder a los interrogantes que puedan plantearse, sino más bien dejar constancia de cuáles siguen siendo éstos para nosotros. Sin que todo ello reste valor a un trabajo con el que hemos disfrutado y que recomendamos. En definitiva, si este libro es importante, es porque no sólo nos da contenidos y respuestas a algunas cuestiones, sino sobre todo porque nos obliga a plantearnos ciertas preguntas.

Una de las primeras dudas que se nos plantean es la utilización del término burguesía y, más concretamente, «burguesía feudal», para referirse a la oligarquía urbana que controla el Ayuntamiento madrileño a lo largo de los siglos XVII y XVIII. Son dos los criterios que, a nuestro modo de ver, utiliza para definirla de ese modo: uno económico-social, en relación con lo que es su actividad productiva y sus inversiones, perfectamente insertadas en las prácticas del Antiguo Régimen; otro ideológico-político, ligado a la ausencia de un proyecto propio, y a su apuesta por el proyecto refeudalizador que implicó según el autor- la Monarquía absoluta. En cualquier caso, uno y otro se confunden con frecuencia. Mauro Hernández toma la definición de "burguesía feudal" del trabajo de Barel sobre la ciudad medieval ${ }^{4}$ (quien a su vez lo toma de Porshnev y éste de Engels) y dice de él que "le va como anillo al dedo a la oligarquía madrileña y a las oligarquías urbanas de la corona de Castilla » (pág. 277). Es un concepto "útil» dada su eficacia para describir "una clase social que parece sumamente escurridiza", y porque permite "prescindir de la noción de traición de la burguesía", de evidente origen braudeliano, deberíamos añadir ${ }^{5}$. Con ello, el autor insiste en lo que es su rasgo fundamental: «la apuesta de esta burguesía por el proyecto de territorialización del Estado feudal» (pág. 276). La "cuestión del poder urbano» puede afrontarse así de modo diferente, no desde la confrontación con la Monarquía, sino desde la comunión de intereses, tanto en el ámbito socio-económico - sistema feudal一, como en el político - territorialización del poder.

Encontramos en este punto un esfuerzo que, si no es baldío, resulta poco rentable desde el punto de vista de lo que son los resultados de la investigación. El mismo autor reconoce las dificultades que comporta uencasillar» la poco regular trayectoria vital de los regidores en uno u otro término. Como mucho, advierte, se puede llegar a «depurar la clasificación». Esta depuración le permite decir que los tipos "genuinamente burgueses» están ausentes del Concejo madrileño durante el período estudiado, o que son muy pocos. Una afirmación de estas características es ciertamente problemática porque supone un anacronismo e, implica, juzgar desde categorías y taxonomías

4 Barel, Y., La ciudad medieval. Sistema social-sistema urbano. Madrid, 1981.

5 BRAUDEL, F., El Mediterráneo y el mundo mediterráneo en la época de Felipe II. Madrid, Fondo de Cultura Económica, 1980, vol. II, págs. !04 y ss. Una revisión del propio Braudel sobre la «traición de la burguesia» en Braudel, F., La dinámica del capitalismo. México, Fondo de Cultura Económica, 1986.

Hisponia, LVl/3, núm. 194 (1996) 1121-1131 
sociales que son las del xIX y para el siglo xIx: lo "genuinamente burgués" hace tiempo que es objeto de discusión en las ciencias sociales y en la historiografía, y, en todo caso, su construcción y definición, que debemos, entre otros, a Marx y a los sociólogos de la tradición alemana (Sombart y Weber) se hacen a partir de tipos ideales, extraños a los procesos reales ${ }^{6 .}$

En cualquier caso, para Mauro Hernández el dato realmente sobresaliente es que la burguesía que ejerce los cargos de regidor está - como ya hemos adelantado- - "perfectamente inmersa en la prácticas económicas y sociales del Antiguo Régimen». Pues bien, ¿no será ésta la burguesía "Antiguo Régimen» acuñada hace ya bastante tiempo por Regine Robin en un artículo que provocó no pocas discusiones, por lo demás hoy ya bastante superadas? ".

Con esto no queremos dar a entender que no sea necesario designar, conceptualizar y precisar al máximo posible los contenidos del trabajo histórico. Ahora bien, siempre y cuando ello no nos impida, precisamente, seguir el rastro cambiante de un sector social que se constituye, como todos, en un proceso específico. De hecho, como señalaba Thompson, los conceptos históricos son útiles si incorporan la historicidad, es decir, la peculiaridad espacio-temporal y la interioridad, esto es, si se elaboran teniendo en cuenta la autopercepción de los propios protagonistas. En ese caso, como apostillaba el historiador inglés, el contexto es la clave del significado histórico ${ }^{8}$.

Estas evidencias, que son generales y productivas para el análisis social, son igualmente importantes para la descripción y el estudio de la oligarquía madrileña, que vivirá, es cierto, "a la sombra de la Corona», y que ligará su destino al del absolutismo. Siendo éste bastante incierto, no podía serlo menos el de esos burgueses, sobre todo cuando sus interese privados, patrimoniales, se adentran en el camino de la crisis. ¿Permanecerán pasivos, dejándose arrastrar por lo que parece ineludible? Nos atrevemos a decir que no; al menos no todos los miembros de ese grupo. El propio autor nos informa, precisamente, de actitudes que van a distar bastante de lo que venían siendo comportamientos ajenos a la producción, en sentido estricto, y meramente rentistas.

Quizá, uno de los ejemplos que podemos utilizar para reforzar esto último sea el del marqués de Perales, que en pleno siglo xviII es capaz de invertir en uno de los bienes más preciados durante el setecientos: la tierra. Pero sus inversiones no serán cualquier cosa. Uno de los lugares escogidos fue, al pare-

- Cf. al respecto, SERNA, J. y Pons. A., «El nombre del burgués», en Bonamusa, F. y Serrallonga, J. (eds.), La sociedad urbana. Barcelona, Asociación de Historia Contemporánea, 1994, págs. 81130. Romanelll, R., "Borghesia/Butgentum/Bourgeoisie. Itinerari europei di un concepto", en KockA, J. (eds.), Borghesie europee dell'Nottocento. Venecia, Marsilio, 1989, págs. 69-94.

7 Rosin, R., «La naturaleza del Estado a finales del Antiguo Régimen: formación social, Estado y transición), en AA.VV., Estudios sobre la Revolución Francesa y el final del Antiguo Régimen. Madrid, Akal, 1980, págs. 91-92.

8 Thompson, E. P., Miseria de la teoría. Barcelona, Crítica, 1981. ld., "L'antropología e la disciplina del contesto storicon, en Società patrizia, cultura plebea. Turín, Einaudi, 1981, págs. 251-273. 
cer, la huerta de Valencia, y más concretamente, las tierras arrozales del lago de la Albufera, pertenecientes al Real Patrimonio. En ellas llegará a situarse entre los mayores propietarios, ya desde la década de los sesenta. En la centuria siguiente, en 1836, un miembro de la familia Pinedo sigue situándose entre los primeros terratenientes del lago ${ }^{9}$. La compra de una plaza de regidor en el Ayuntamiento de Valencia, en 1791, los vinculará, también aquí, al desempeño de cargos políticos a escala local ${ }^{10}$. Este tipo de información, aun a falta de contrastarla con diversas fuentes, no parece alejarse de lo que fue la dinámica del titular del marquesado: fundar mayorazgos para sus hijos y desvincular ciertos bienes altamente valorados, para comprar otros, sobre todo tierras (pág 142).

Por tanto, y siguiendo lo que es también un planteamiento del autor, a lo largo de casi dos siglos se observan importantes cambios en la actitud y comportamientos económicos de la oligarquía madrileña, de corte básicamente rentista y feudal. Aunque no sólo, deberíamos añadir. En efecto, la tierra no se encuentra en todo ese tiempo entre los bienes más sustanciosos que conforman sus patrimonios. Al menos los de ese $10 \%$ de regidores que la documentación -mucho más abundante para el siglo xvil que para el xviI- le ha permitido estudiar. Mauro Hernández ha podido constatar que esta oligarquía renunció a disputarle a la nobleza la propiedad de la tierra. Precisamente en un momento en que esa tierra no es un bien rentable. Esto lo dice el autor, pero no hace explícita la relación entre ambos hechos. Quizá, el desinterés no fuera más que coyuntural, y las razones no radicaban, desde luego, en el bien en sí mismo.

A partir de un determinado momento, principalmente tras el cambio de centuria, algunos miembros de la oligarquía vuelven a interesarse por él, y lo buscan allí donde es rentable. El mencionado caso del marqués de Perales es suficientemente significativo. El peso de la propiedad agraria en los patrimonios de la oligarquía de regidores de otras ciudades de la monarquía ", desde antes del siglo xviI, o durante el mismo, además de advertimos sobre la cautela que se ha de tener a la hora de extrapolar los resultados de una investigación concreta -y el autor demuestra tenerla--, nos sitúa, una vez más, ante la conveniencia del estudio comparativo. Contrastar los resultados de distintos trabajos, en este caso sobre ciudades diferentes, nos puede y nos debe llevar a un conocimiento más preciso, a la vez más complejo y matizado de dichas oligarquías y de su papel en el seno de la Monarquía absoluta: gracias a ello, no sólo sabremos más, sino que, a la vez, sabremos lo que no sabemos.

Que crecieron al amparo de la institución monárquica y que le sirvieron de apoyo es algo que parece confirmarse en términos generales. Que murieran

9 Garcla MonerRis, C., Rey y señor. Estudio de un realengo del País Valenciano. (La Albufera 176/-1836). Valencia, Ayuntamiento de Valencia, 1985, págs. 161, 162, 221 y 222.

10 Garcia Monerris, E., La Monarguía absoluta...

1 Pérez PICAzo, M. ${ }^{2}$ T., «La pequena nobleza urbana en la transición del antiguo al nuevo régimen, 1750-1850. El caso de Murcia», en Les noblesses européennes au XIX siècle. Università di Milano, École Française de Rome, 1988, págs. 473-528.

Hispaniu, LVU/, nưm. 194 (1996) 1121-1131 
con aquélla o que no se enfrentaran al orden tardofeudal no está tan claro. ¿Cómo explicar, por ejemplo, que las oligarquías de regidores murcianos pasaran de ser "verdadero nervio de la Monarquía antiguo-regimental", a miembros «sin solución de continuidad con el período anterior", de los primeros Ayuntamientos constitucionales»? ${ }^{12}, O$, ¿qué lectura debemos hacer de lo que ocurre en Valencia? En este caso, aun a falta de estudios monográficos en profundidad para el siglo XIX, puede decirse que no fueron pocos los casos de familias de regidores que, tras medrar con y junto a la Monarquía absoluta, consiguen salir airosos de la quiebra del Antiguo Régimen, tanto por lo que a sus intereses económicos se refiere -en relación con la naturaleza de sus bienes y con el peculiar proceso de descomposición del feudalismo-, como a sus intenciones políticas. En este sentido, la opción liberal moderada no les será ajena; en gran parte, porque les iba a permitir consolidar sus propiedades. Unas propiedades que habían ido adquiriendo precisamente, y en su mayor parte, durante el siglo xviII ${ }^{13}$. No fue tarde, pues, como llega a afirmar el autor, para plantear un modelo alternativo que superara la crisis mediante la vuelta a la producción (pág. 149). En muchos casos sí que fue posible, como lo fueron ciertas reformas introducidas por la Monarquía, al margen del mayor o menor éxito de las mismas. Porque, conscientes precisamente unos y otros de la crisis, tratan de buscar soluciones dentro del propio sistema. Otra cuestión es que tales soluciones prepararan o precipitaran una quiebra definitiva de la que no podían aún tener constancia.

Estamos, pues, ante un sector clave de la sociedad española en los últimos momentos del Antiguo Régimen que, desde el control de la vida política local, forjó sus patrimonios y su status. En definitiva, un ámbito de actuación y de intereses privados que no nos permite hablar en términos de que la burguesía se "traicionó" a sí misma, o que "traicionó" al tercer estado, dejando de jugar un papel subversivo del orden feudal en crisis. Desde la heterogenidad que caracteriza a este grupo, puede decirse que se enfrentó a aquél cuando y donde lo consideró conveniente en función de sus intereses. En cualquier caso parece estar bastante claro que no podemos seguir pensando en términos de papeles históricamente asignados a unos grupos o clases específicos. Las relaciones entre la Monarquía y las diversas oligarquías locales fueron lo suficientemente ambivalentes y contradictorias como para que reduzcamos sus comportamientos a estereotipos inexistentes.

A pesar del control de la Corona sobre los municipios, no cabe duda, como el propio autor resalta, que éstos «conservaron importantes parcelas de poder", y que, en cualquier caso, la existencia de un mayor o menor grado de autonomía local debe buscarse "más en la práctica de la administración" y no tanto en su regulación legal o "en los conflictos con el Estado». Por nuestra

12 lbid.

13 Un ejemplo significativo puede ser el barón de Santa Bárbara. Cf. al respecto, GARCía MonERRIS, E. y SERNA ALONSO, J., «Tertius gaudens. El Baró de Santa Bárbara o la mediació com a professió», Afers, núm. 16, Valencia, 1993, págs. 33l-345. 
parte, consideramos que cualquiera de estas manifestaciones es necesaria a la hora de calibrar esa autonomía. Sin embargo, no es tanto en esto en lo que quisiéramos centrarnos, como en alguna de las consecuencias de la centralización del setecientos en materia de oficios municipales. En el caso madrileño, Mauro Hernández constata una cierta caída del interés por estos cargos, coincidiendo más o menos con la «ofensiva centralizadora de los Borbones». La caída de los precios con los que se enajenaban y la existencia de un mayor número de vacantes fueron dos de sus manifestaciones, al tiempo que respondían a lo que, en términos lógicos, era una merma de las facultades de autogobierno y, por tanto, de las posibilidades de controlar no pocas de las facetas clave que conformaban la vida de los Concejos, como la gestión de la hacienda, por poner sólo un ejemplo.

En este punto debemos insistir una vez más en la necesidad de cotejar tales actitudes con las de otras oligarquías. El caso de Valencia nos muestra una realidad bastante diferente, en parte, a la de la capital. La venta de oficios municipales se produce años después de la abolición del régimen foral (1707) y tras comprobar, en la práctica, que gran parte de la nobleza valenciana rechaza el ofrecimiento que nada más finalizado el conflicto le hace la Corona. Tal ofrecimiento había consistido en un considerable número de plazas de regidor en el Ayuntamiento de Valencia. Las continuas vacantes y ausencias, la desidia a la hora de tomar posesión del cargo y, cómo no, la necesidad de la nueva dinastía de obtener ingresos y, sobre todo, ganarse adeptos, conducen a la enajenación de parte de las plazas. El elevado número de pretendientes a las mismas y su precio revelan todo, menos desinterés. Es más, éste sigue siendo alto incluso en las postrimerías del siglo, cuando su venta entre particulares llega a triplicarlo ${ }^{14}$. En este caso, pues, la ofensiva centralizadora no constituyó un factor de inhibición hacia este tipo de oficios. Sí lo fue, por el contrario, durante las dos primeras décadas del siglo, para destacados miembros del estamento nobiliario.

Otra cuestión no menos importante llama nuestra atención. Nos referimos al tema de la «refeudalización» que comporta el absolutismo. Se trata de algo que no acabamos de ver demasiado claro, sobre todo si atendemos a algunas de las prácticas emprendidas por la Monarquía, y en particular bajo Carlos III. Cuando éste pone en marcha las reformas hacendísticas locales, cuando la hacienda real empieza a ser denominada y a considerarse -aunque con cautela y falta de claridad- "pública", ¿podemos considerar esto como refeudalización? El mismo patrimonialismo de que hace gala la Corona, tanto tras la guerra, como en la década de los sesenta, en relación a su Real Patrimonio, ¿debe ser contemplado desde la óptica de la refeudalización? ¿Acaso no fueron las consecuencias de este proceso bastante distintas y complejas? Sobre el particular se ha escrito, entre otras cosas, lo siguiente ${ }^{15}$ :

14 Garcja Monerris, E., La Monarquía absoluta..."

I5 Garcia Monerris, C., "Algunas reflexiones en tomo al Real Patrimonio y el feudalismo valenciano", Estudis d'Història Contemporània del País Valencià, núm. 5. Valencia, Universidad de Valencia, 1984, pág. 19.

Hispania, LVI/3, núm. 194 (1996) 1121-1131 
"Por paradójico que pueda parecer, la recuperación o normaljzación de las rentas patrimoniales en las Bailfas, cuya capitalidad la ostentaba evidentemente una ciudad realenga, corrió paralela, en su momento de máxima intensidad, con el proceso de mayor control y dominio de los Ayuntamientos de dichas ciudades por parte de la monarquía. La paradoja debe entenderse, en todo caso, en el sentido de la confluencia sobre un mismo espacio político y económico de una supuesta doble intencionalidad areformadora»: la que dimanaba de los intereses fiscales y "estatales" y la que dimanaba de los intereses patrimoniales y "particularesn.

La aparente confusión entre «res publica» y "res Patrimonialia», no debe llevarnos a la aceptación indiscriminada de un absolutismo monárquico que se construye a sí mismo en términos estatalistas. Sin embargo, sí debería advertirnos de que estamos ante un "proyecto"-si es que podemos considerarlo como tal- que tiene más de modernizador que de refeudalizador.

Finalmente, no podemos dejar de plantear algunas cuestiones que son más fruto de nuestras dudas y de las múltiples sugerencias que se derivan del libro de Mauro Hernández, que no reproches o críticas. En primer lugar, nos hubiera gustado encontrar una mayor presencia del siglo xviII en el texto. Es cierto que el estudio que realiza sobre la oligarquía madrileña comprende también esta centuria. Sin embargo, creemos que la subestima, amparándose en lo que el autor considera que fueron reformas frustradas. Quizá, una ojeada a lo que el cambio dinástico implicó en otros territorios de la Monarquía, como los integrantes de la antigua Corona de Aragón, pudiera servir para valorar en términos no tan negativos los resultados - históricamente considerados- del reformismo borbónico. Nos da la impresión que el trabajo se inclina más hacia el siglo xvI, y que es esta centuria y los resultados de la misma, por lo que a la oligarquía se refiere, la que, puede estar empañando cambios importantes acaecidos durante el setecientos, sobre todo en su segunda mitad.

En segundo y último lugar, echamos en falta, o nos gustaría saber, qué tipo de relación tiene esa oligarquía con el resto del cuerpo social, cómo ejerce el poder desde el Concejo y desde sus puestos de regidor, más allá de la gestión de sus intereses privados. Al comienzo del libro, Mauro Hernández nos advierte que se trata de un trabajo de historia social y no de historia institucional. Es cierto, pero desde el momento en que tal grupo se hace a sí mismo en y desde el control de la administración, por mucho que ésta tenga todavía un carácter patrimonial, no estaría de más saber cómo gobiernan y qué conflictos se derivan de esa praxis de gobiemo, tanto en relación con otros grupos sociales, como con la Monarquía.

En cualquier caso, y al margen de las observaciones o dudas que hemos ido planteando, es ésta una investigación con la que tanto modernistas como contemporaneístas deberán contar. No sólo por aquéllo que nos desvela sobre el Madrid de la Edad Moderna, sino también por su rigor metodológico, por la cautela y precisión con que trata los datos que las fuentes le ofrecen, y por el entusiasmo que, al menos nosotros, hemos creído descubrir en la escritura de las más de cuatrocientas páginas que lo constituyen. 